\title{
Thermally Stimulated Evolution of Optical and Structural Properties of Germanium-Doped Alumina Films
}

\author{
L. Khomenkova a,b, K. Makasheva ${ }^{\mathrm{c}}$, P. Petrik ${ }^{\mathrm{d}}$, C. Bonafos $^{\mathrm{e}}$, N. Ratel-Ramond ${ }^{\mathrm{e}}$, \\ O. Melnichuk ${ }^{f}$ L. Melnichuk ${ }^{f}$ I. Balberg ${ }^{g}$, F. Gourbilleau ${ }^{\text {, }}$, and N. Korsunska ${ }^{\text {a }}$ \\ ${ }^{a}$ V. Lashkaryov Institute of Semiconductor Physics, 45 Pr. Nauky, Kyiv 03028, Ukraine \\ ${ }^{b}$ National university "Kyiv-Mohyla academy”, 2 Skovorody str., Kyiv 04070, Ukraine \\ ${ }^{\mathrm{c}}$ LAPLACE, Université de Toulouse, CNRS, UPS, INPT, \\ 118 route de Narbonne, 31062 Toulouse, France \\ d Institute for Technical Physics and Materials Science, Center for Energy Research, \\ Konkoly Thege Rd. 29-33, 1121 Budapest, Hungary \\ ${ }^{\mathrm{e}}$ CEMES/CNRS, 29 rue Jeanne Marvig, 31055 Toulouse Cedex 4, France \\ ${ }^{g}$ Mycola Gogol Nizhyn State University, 2 Grafska str, Nizhyn 16600, Ukraine \\ ${ }^{\mathrm{f}}$ Racah Institute of Physics, Hebrew University, Givat Ram, Jerusalem, Israel \\ ${ }^{\mathrm{h}}$ CIMAP, Normandie Univ, ENSICAEN, UNICAEN, CEA, CNRS, \\ 6 Boulevard Maréchal Juin, 14050 Caen Cedex 4, France
}

Ge-doped $\mathrm{Al}_{2} \mathrm{O}_{3}$ films were deposited on long, non-rotated quarts substrate by magnetron co-sputtering of $\mathrm{Ge}$ and $\mathrm{Al}_{2} \mathrm{O}_{3}$ space-apart targets. This approach allowed to vary Ge content along the film length in the range 5-85 at.\%. Simultaneous annealing treatment of such long samples permitted to investigate the evolution of optical and structural properties of the films with different Ge content. It was observed that all as-deposited films and those annealed at $\mathrm{T}_{\mathrm{A}}=550{ }^{\circ} \mathrm{C}$ during $50 \mathrm{~min}$ in nitrogen atmosphere were amorphous whatever $\mathrm{Ge}$ content. The formation of $\mathrm{Ge}$ nanocrystals was observed after treatment at $\mathrm{T}_{\mathrm{A}}=600{ }^{\circ} \mathrm{C}$ during $1-15 \mathrm{~min}$. The higher Ge content, the shorter annealing time was required to form Ge nanocrystals. This annealing stimulated also an appearance of photoluminescence in visible-near infrared spectral range. Three specific bands centered at about 580-600 nm, 620-630 nm and 700-730 nm were detected. Their relative contribution was depended on Ge content determining the shape and peak position of luminescence spectrum. Two former components were ascribed to the carrier recombination via the defects in Ge oxide shell covered Ge nanocrystals, whereas the latter one was assumed to originate from carrier recombination in amorphous Ge clusters or via defects at $\mathrm{Ge}$-cluster $/ \mathrm{Al}_{2} \mathrm{O}_{3}$ interface. This statement was supported by the heat treatment of the films at $\mathrm{T}_{\mathrm{A}}=700-800{ }^{\circ} \mathrm{C}$ caused significant decrease of Ge content due to $\mathrm{Ge}$ out-diffusion from film volume via formation of volatile $\mathrm{GeO}$.

\section{Introduction}

In recent decades, significant attention of research groups has been focused on silicon or germanium nanostructured materials. Since the first report on nanostructured Si-based 
materials $(1,2)$, optical and structural properties of free standing silicon nanocrystallites (Si-ncs) or those embedded in dielectric hosts were widely studied (3-10). A lot of efforts were concentrated on the development of different technological approaches for fabrication of Si-ncs, monitoring their size distribution and surface chemistry. An optical gain and electroluminescent emission were achieved offering the perspective to create all-in-one-chip Si-based optoelectronic devices. Significant knowledge on the light emission processes of Si nanostructured materials was obtained. The mechanisms of Sincs formation in different hosts were proposed.

It is interesting that size-dependent optical properties of germanium nanocrystals (Ge-ncs) were reported by Hayashi et al. much earlier than those of Si-ncs (11). Although the Ge-ncs were also studied by different research groups (see, for instance, 12-22), the corresponding publications were not so numerous unlike those on the Si-ncs embedded in different hosts. Recently, the attention of the researchers has been particularly renewed towards the Ge-ncs since they are environmentally friendlier alternatives to classical compound semiconductor nanocrystals being nontoxic, biocompatible, electrochemically stable and compatible with current microelectronics. The investigation of either freestanding Ge-ncs or those embedded in dielectric hosts was reported (23-28).

As compared to silicon, germanium is especially appealing due to the larger dielectric constant, higher electron and hole mobility, smaller effective masses of electrons and holes. A narrower bulk band gap (0.66 eV for Ge against $1.1 \mathrm{eV}$ for $\mathrm{Si})$ and a larger absorption coefficient offered a possibility for tuning of light emission in wider spectra range. Bohr exciton radius of germanium, $r_{\mathrm{B}}^{\mathrm{Ge}}=24.3 \mathrm{~nm}$, is significantly larger than that of silicon $\left(r_{\mathrm{B}} \mathrm{Si}=4.5 \mathrm{~nm}\right)(12)$. This means that Ge-ncs will impart stronger, more easily identified quantum confinement effects than Si-ncs with the same sizes. Moreover, quantum confinement effects will emerge for larger Ge-ncs than that for Si-ncs (25). Due to this property, the Ge-ncs are considered to be ideal nodes for memory devices $(17,21,23,26)$. Being crystallized at lower temperature and offering a negative conduction band offset with respect to the Si substrate, the Ge-ncs provide a larger memory window than devices based on Si-ncs with improved retention time $(16,21)$.

The Ge-ncs embedded in $\mathrm{SiO}_{2}$ host were mainly studied. However, $\mathrm{Al}_{2} \mathrm{O}_{3}$ is an interesting material not only for microelectronic application, but also for optical communication due to its relatively higher refractive index $(1.73$ at $1.95 \mathrm{eV})$ in comparison with that of $\mathrm{SiO}_{2}(1.46$ at $1.95 \mathrm{eV})$ offering better light confinement. Although $\mathrm{Al}_{2} \mathrm{O}_{3}$ waveguides doped with $\mathrm{Si}$ or $\mathrm{Ge}$ and rare-earth ions were developed for optical communications (28,31), such materials are still less addressed. The present paper reports the fabrication of Ge-doped $\mathrm{Al}_{2} \mathrm{O}_{3}$ films with different $\mathrm{Ge}$ content by magnetron co-sputtering and the effect of post-deposition processing on the structural and optical properties of these materials.

\section{Experimental details}

Ge-rich $\mathrm{Al}_{2} \mathrm{O}_{3}$ films were deposited on long non-rotated quarts substrates by radiofrequency magnetron sputtering of two spatially separated targets, pure Ge and pure $\mathrm{Al}_{2} \mathrm{O}_{3}$. The diameter of each target was 2 inches. The length of quartz substrate was 15 $\mathrm{cm}$. The distance between the targets and the substrate was $13 \mathrm{~cm}$. The sputtering was 
performed in an argon atmosphere at a pressure of $1.1 \mathrm{~Pa}$ for 250 minutes. The power densities applied to $\mathrm{Al}_{2} \mathrm{O}_{3}$ and $\mathrm{Ge}$ targets were 0.98 and $0.49 \mathrm{~W} / \mathrm{cm}^{2}$, respectively. The substrate temperature was $15^{\circ} \mathrm{C}$. Using this deposition approach, the films with variation of $\mathrm{Ge}$ content along the film length were obtained. Besides, pure $\mathrm{Ge}$ and pure $\mathrm{Al}_{2} \mathrm{O}_{3}$ films were also produced by the sputtering of corresponding target only at the same conditions. More details about this approach can be found in (27). To form Ge-ncs, the heat treatment of the films was performed in conventional horizontal furnace at $\mathrm{T}_{\mathrm{A}}=500$ $800{ }^{\circ} \mathrm{C}$ during 1-50 min in nitrogen atmosphere.

Optical and structural properties of the films were studied by spectroscopic ellipsometry, Raman scattering, X-ray diffraction (XRD) and photoluminescence (PL) methods. Spectroscopic ellipsometry measurement was performed by means of a JobinYvon ellipsometer (UVISEL, HORIBA Ltd., Kyoto, Japan), where the incident light was scanned in the range of 1.5 to $4.5 \mathrm{eV}$ under an incident angle of $66.3^{\circ}$. The fitting of the experimental data was performed using DeltaPsi2 software (HORIBA Ltd., Kyoto, Japan). The refractive indexes are reported being taken at $1.95 \mathrm{eV}$. Raman scattering and photoluminescence spectra were recorded with a double grating monochromator equipped with CCD camera. Solid-state laser with the 532-nm wavelength was used as excitation source. The power density of this excitation light was chosen to prevent any heating of the films during spectrum recording. XRD data were collected in a $2 \theta$ range of $20^{\circ}-80^{\circ}$ with $\mathrm{Cu} \mathrm{K} \mathrm{K}_{\alpha}$ radiation $(0.1514 \mathrm{~nm})$ of a Philips X'PERT HPD Pro device. An asymmetric grazing geometry $\left(\omega \sim 0.5^{\circ}\right)$ was chosen to increase the volume of material interacting with the X-ray beam. The data were compared with standard cards of Powder Diffraction File Database (\#4-0545 for cubic Ge). All measurements were performed at room temperature. The combination of these non-destructive methods allows information about microstructural and optical properties of the films to be obtained.

\section{Spectroscopic ellipsometry}

\section{Results and discussion}

Being a fast, sensitive, and non-destructive method, spectroscopic ellipsometry is used for the determination of the thickness of thin film and its optical parameters (such as refractive index, $n$, and absorption coefficient, $\alpha$ ). The fitting of experimental data obtained for $\mathrm{Ge}_{-} \mathrm{Al}_{2} \mathrm{O}_{3}$ films as well as pure Ge and pure $\mathrm{Al}_{2} \mathrm{O}_{3}$ counterparts was performed using the approach described in (4,7). For pure $\mathrm{Ge}$ and pure $\mathrm{Al}_{2} \mathrm{O}_{3}$ films the refractive indexes (taken at $1.95 \mathrm{eV}$ ) were estimated as $n_{\mathrm{Ge}}=4.21 \pm 0.01$ and $n_{\mathrm{Al}_{2} \mathrm{O} 3}=1.75 \pm 0.01$, respectively. The fitting of the spectra of $\mathrm{Ge}_{x}\left(\mathrm{Al}_{2} \mathrm{O}_{3}\right)_{1-x}$ film deposited on long substrate revealed the variation of the refractive index (taken at $1.95 \mathrm{eV}$ ) from $n=1.81 \pm 0.01\left(\mathrm{Al}_{2} \mathrm{O}_{3}\right.$-rich side) up to $n=3.85 \pm 0.01$ (Ge-rich side) along the film length. The thickness of the films was varied from $450 \pm 5 \mathrm{~nm}\left(\mathrm{Al}_{2} \mathrm{O}_{3}\right.$-rich side) up $1300 \pm 10 \mathrm{~nm}$ (Ge-rich side). This thickness variation was caused by the higher sputtering yield of $\mathrm{Ge}$ target in comparison with that of $\mathrm{Al}_{2} \mathrm{O}_{3}$ one.

Earlier, we have shown that for composite Si-rich $\mathrm{Al}_{2} \mathrm{O}_{3}$ and Si-rich $\mathrm{HfO}_{2}$ thin films grown by magnetron sputtering, the use of the effective medium approximation permits to determine the relationship between the refractive index $n$ and film stoichiometry $x$ $(4,7,30,31)$. The same procedure was applied in present study for Ge-rich $\mathrm{Al}_{2} \mathrm{O}_{3}$ films. Since the experimental spectra were featureless, this allowed assuming that the films are 
amorphous and can be considered as an effective medium which dielectric constant is determined by the relative contribution of $\mathrm{Ge}$ and $\mathrm{Al}_{2} \mathrm{O}_{3}$ components as

$$
x \frac{\varepsilon_{\mathrm{Ge}}-\varepsilon_{e f f}}{\varepsilon_{\mathrm{Ge}}+2 \varepsilon_{e f f}}+(1-x) \frac{\varepsilon_{\mathrm{Al}_{2} \mathrm{O}_{3}}-\varepsilon_{e f f}}{\varepsilon_{\mathrm{Al}_{2} \mathrm{O}_{3}}+2 \varepsilon_{e f f}}=0
$$

where $\varepsilon_{\text {eff }}$ is the dielectric permittivity of composite material, $\varepsilon_{\mathrm{Ge}}$ and $\varepsilon_{\mathrm{Al}_{2} \mathrm{O} 3}$ are the dielectric permittivity of $\mathrm{Ge}$ and $\mathrm{Al}_{2} \mathrm{O}_{3}$, respectively, and $x$ is the fraction of the Ge component. Thus, our Ge-rich films can be considered as $\mathrm{Ge}_{x}\left(\mathrm{Al}_{2} \mathrm{O}_{3}\right)_{1-x}$ medium. Taking into account the $n$ values obtained by the fitting of experimental ellipsometry spectra, the $x$ values of $\mathrm{Ge}_{x}\left(\mathrm{Al}_{2} \mathrm{O}_{3}\right)_{1-x}$ films were found to vary from $x=0.05$ (at $\mathrm{Al}_{2} \mathrm{O}_{3}$-rich side) up to $x=0.85$ (at Ge-rich side). It should be noted that the films with $x>0.7$ can be considered rather as a Ge film enriched with $\mathrm{Al}_{2} \mathrm{O}_{3}$, than $\mathrm{Al}_{2} \mathrm{O}_{3}$ host doped with Ge.

\section{$\underline{\text { Raman scattering spectra }}$}

As-deposited $\mathrm{Ge}_{x}\left(\mathrm{Al}_{2} \mathrm{O}_{3}\right)_{1-x}$ films were found to be amorphous. For the films with $x>0.6$, the peak position of Ge TO phonon was found at $\omega_{\mathrm{TO}} \approx 270-274 \mathrm{~cm}^{-1}$ (Fig. 1,a). This spectral position is similar to that observed in amorphous germanium. When Ge content decreases to $x=0.1$, the broadening of Raman scattering spectrum and shift of the $\omega_{\text {TO }}$ down to $268 \mathrm{~cm}^{-1}$ were observed. This shift is the evidence that the structure of the films was unrelaxed. This can be caused by the presence of point defects as well as by the tensile stress appeared due to mismatching between the lattice parameters of Ge $(a=0.566$ $\mathrm{nm})$ and $\mathrm{Al}_{2} \mathrm{O}_{3}(a=0.792 \mathrm{~nm}$ for cubic; $a=0.475 \mathrm{~nm}, c=1.299 \mathrm{~nm}$ for hexagonal alumina (32)). It should be noted that Raman scattering spectra for the films with $x<0$.1 were not recorded due to high transparency of the films. Significant contribution of amorphous $\mathrm{Ge}$ phase in the films with $x \geq 0.2$ (Fig.1,a) testifies to the formation of Ge amorphous inclusions during deposition process similar to the effect reported for Si-rich $\mathrm{Al}_{2} \mathrm{O}_{3}$ films $(4,7,10,27)$.
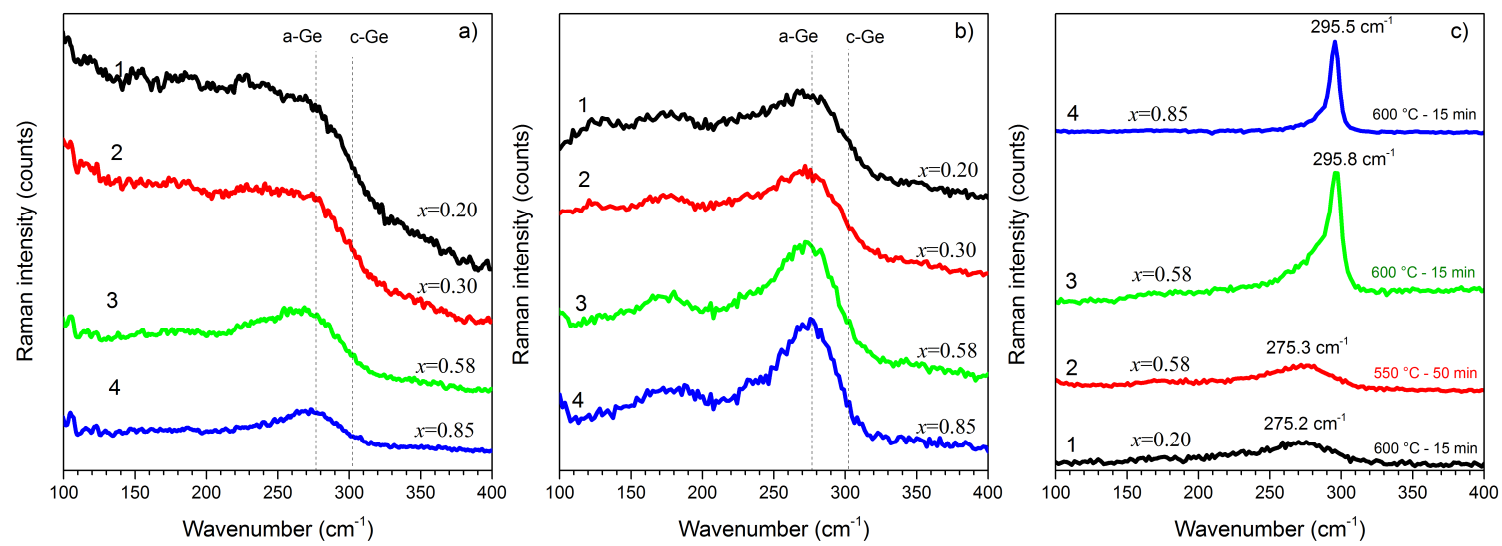

Figure 1. Raman scattering spectra of as-deposited samples (a) and those annealed at $\mathrm{T}_{\mathrm{A}}=550{ }^{\circ} \mathrm{C}$ for $50 \mathrm{~min}$ (b) and $600{ }^{\circ} \mathrm{C}$ for $15 \mathrm{~min}$ (c). The Ge content is mentioned in the figures. The spectra are vertically shifted for clarity. The vertical dashed lines show the peak position of Raman signal for amorphous (a-Ge) and bulk (c-Ge) germanium. 
The heat treatment of the films at $\mathrm{T}_{\mathrm{A}}=500{ }^{\circ} \mathrm{C}$ did not affect film structure. Whatever annealing time, all these films kept amorphous nature. The $\mathrm{T}_{\mathrm{A}}$ rise up to $550^{\circ} \mathrm{C}$ led to the increase of the intensity of Raman signal and its narrowing accompanied by the shift of peak position towards higher wavenumbers $\left(\omega_{\mathrm{TO}} \approx 272-275 \mathrm{~cm}^{-1}\right)$ that is the evidence of the stress relaxation. This transformation of Raman spectra was more pronounced for the films with $x<0.6$ (Fig. 1,b). The longer annealing time enhanced this effect. It should be noted that these annealed films became more transparent that can be caused by the formation of $\mathrm{Ge}$ clusters as well as appearance of $\mathrm{GeO}_{2}$ due to phase separation process. It is worth to point out that the formation of volatile $\mathrm{GeO}$ can be ruled out for this annealing temperature.

Annealing of the films at $\mathrm{T}_{\mathrm{A}}=600{ }^{\circ} \mathrm{C}$ resulted in further narrowing of Raman signal and its shift towards $\omega_{\mathrm{TO}} \approx 275 \mathrm{~cm}^{-1}$ for $x<0.6$ (Fig.1,c). However, this final peak position showed that whatever annealing time, the Ge inclusions are rather amorphous than nanocrystalline. This result demonstrates that in the contrast to the ability of aluminum to enhance Ge crystallization (33), in our films with $x<0.6$ and annealed at $\mathrm{T}_{\mathrm{A}}=600{ }^{\circ} \mathrm{C}$ amorphous Ge phase is stable. This result was similar to those reported in (34) for Ge$\mathrm{Al}_{2} \mathrm{O}_{3} / \mathrm{Al}_{2} \mathrm{O}_{3}$ superlattices. At the same time the shift of peak position to higher wavenumbers than that of amorphous $\mathrm{Ge}$ is the evidence of full relaxation of tensile stresses and, even, an appearance of compressive ones that can be caused by the transformation of $\mathrm{Al}_{2} \mathrm{O}_{3}$ host as well as by underlying quarts substrate.

In the films with $x>0.6$, the Raman peak showed its narrowing and shift towards $\omega_{\mathrm{TO}} \approx 295 \mathrm{~cm}^{-1}$ (Fig. 1,c) that is the evidence of the crystallization of Ge clusters. It should be noted that the higher Ge content, the more pronounced Ge crystallization takes place and the shorter time is required for Ge-ncs formation. Further increase of $\mathrm{T}_{\mathrm{A}}$ up to 700 $800{ }^{\circ} \mathrm{C}$ caused not only Ge-ncs formation, but also the decrease of Raman signal intensity (not shown here). This phenomenon was explained by the Ge out-diffusion from the films via formation of volatile GeO. The results described above were supported by XRD data.

\section{$\underline{\text { XRD data }}$}

Figure 2,a shows the XRD patterns of as-deposited films with different Ge content. All films demonstrate abroad scattering peak indicating its amorphous nature. Similar XRD patterns were recorded for the films with $x<0.5$ annealed at $\mathrm{T}_{\mathrm{A}}=550$ and $600{ }^{\circ} \mathrm{C}$ (Fig.2,b) At the same time, for the films with $x>0.5$, the appearance of the features at $2 \theta=27.23^{\circ}$ and $50.0^{\circ}$ as well as their enhancement after film annealing at $600{ }^{\circ} \mathrm{C}$ was observed testifying to the formation of Ge inclusions via phase separation. This result is in agreement with Raman scattering data. As one can see from Fig.2, the higher Ge content, the shorter time is required for the formation of Ge crystallites.

Three peaks marked as (111), (220) and (311) in Fig.2b,c are the signature of Gencs formation that are randomly oriented. However, corresponding peak positions are observed at $2 \theta=27.23,45.36$ and $53.70^{\circ}$ for $x=0.58$ (Fig.2,b) and $2 \theta=27.32,45.49$ and $53.80^{\circ}$ for $x=0.85$ (Fig.2,c) being shifted in comparison with those reported for $\mathrm{Ge}$ standard $\left(2 \theta=27.28,45.30\right.$ and $\left.53.68^{\circ}\right)$. This indicates in the presence of residual compressive stress in the films with $x=0.85$. This finding is in agreement with the data that obtained from Raman scattering method (Fig.1,c). 

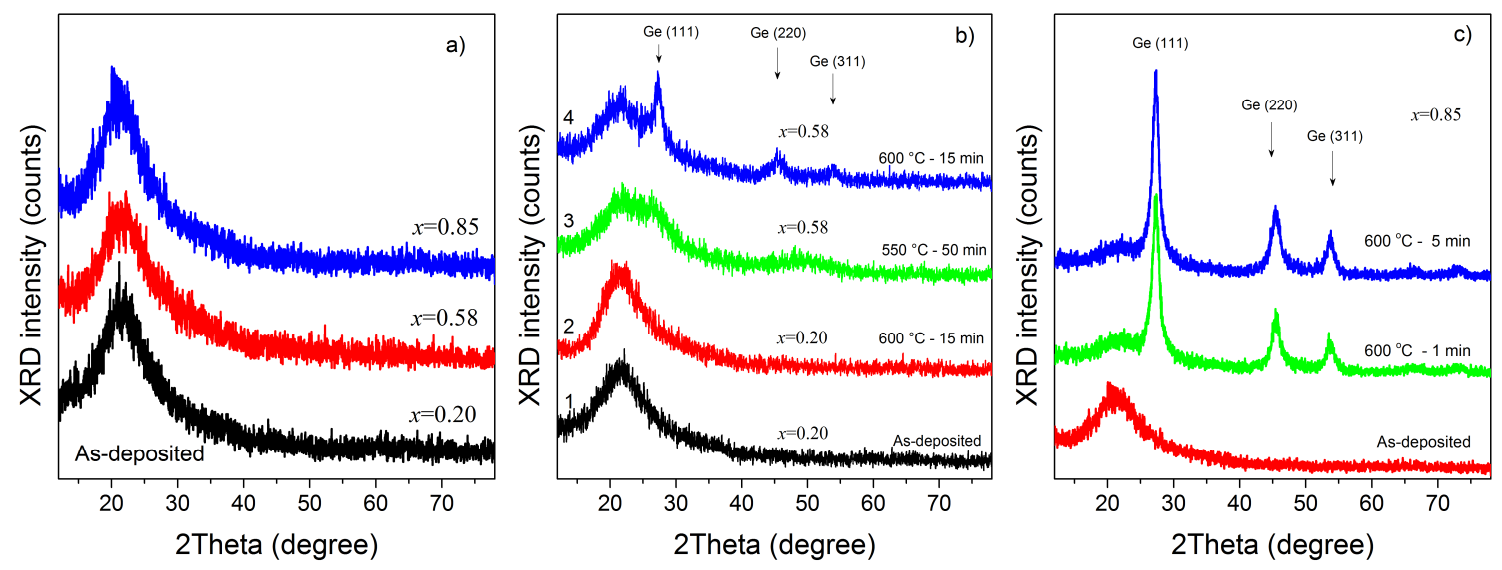

Figure 2. XRD patterns as-deposited (a) and annealed (b,c) films. Annealing parameters and Ge content in the films are mentioned in the figures. The patterns are vertically shifted for clarity.

The estimation of coherent domain sizes, $d$, using Scherrer formula revealed that in the films with $x=0.58$ annealed at $\mathrm{T}_{\mathrm{A}}=600{ }^{\circ} \mathrm{C}$ during $15 \mathrm{~min} d=3.8-4.0 \mathrm{~nm}$. At the same time, for the film with $x=0.85$ annealed at $\mathrm{T}_{\mathrm{A}}=600{ }^{\circ} \mathrm{C}$ during $1 \mathrm{~min} d=4.9-5.0 \mathrm{~nm}$. Longer annealing time $(5 \mathrm{~min})$ resulted in the $d$ increase up to $8.0-8.2 \mathrm{~nm}$. The analysis of the intensities of XRD peaks showed that the Ge-ncs in these films may have elongated shape with large size in (111) direction.

The comparison of XRD and Raman scattering data revealed the discrepancy between Ge-ncs sizes and corresponding Raman peak positions. This is an additional confirmation of the presence of residual stress in Ge-doped $\mathrm{Al}_{2} \mathrm{O}_{3}$ films that brings some difficulty in the estimation of Ge-ncs sizes from Raman scattering spectra. Similar effects have been reported for Ge-doped $\mathrm{HfO}_{2}$ and $\mathrm{Si}$-doped $\mathrm{Al}_{2} \mathrm{O}_{3}$ films by different groups $(7,8,18,27)$. To determine real sizes of $\mathrm{Si}$ or Ge crystallites embedded in these hosts, the investigation of such films with transmission electron microscopy was performed. These studies for our Ge-doped $\mathrm{Al}_{2} \mathrm{O}_{3}$ films are in progress.

\section{$\underline{\text { Photoluminescence }}$}

Photoluminescence (PL) study of as-deposited films revealed a weak PL emission only for the samples with low Ge content $(x<0.2)$. It is peak position was observed at $560-570 \mathrm{~nm}$ and this band was found to be similar to the PL band reported in $(4,7,35)$ for the $\mathrm{F}^{2+}$ centers in $\mathrm{Al}_{2} \mathrm{O}_{3}$ host. The heat treatment at $\mathrm{T}_{\mathrm{A}}=500-550{ }^{\circ} \mathrm{C}$ did not changed the PL spectra of the films (whatever annealing time and Ge content). Further $\mathrm{T}_{\mathrm{A}}$ increase up to $600{ }^{\circ} \mathrm{C}$ caused an appearance of three PL bands peaked at 580-600 nm, 620-630 nm and 700-730 nm (Fig.3). Thus, it is clear that several recombination channels contribute to PL emission. The shape and the intensity of PL spectrum are determined by their relative contribution.

Usually, for the films with embedded Si or Ge nanocrystals, the shift of PL peak position with variation of nanocrystal sizes is expected because of quantum confinement 
effect. Thus, the increase of nanocrystal sizes has to result in the shift of PL peak position towards longer wavelengths $(1-4,7,18)$.
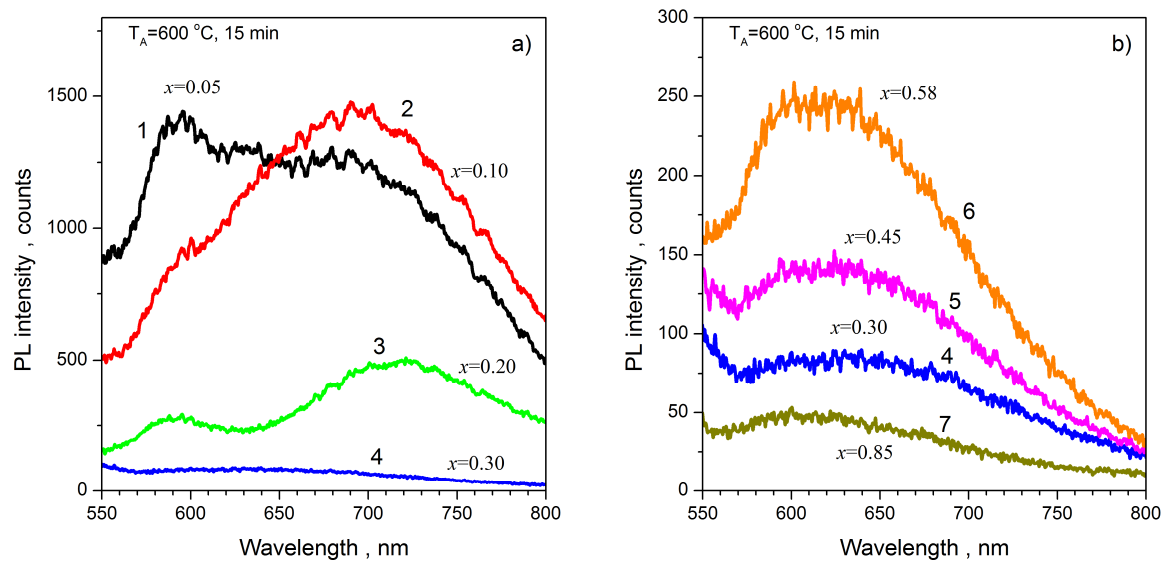

Figure 3. PL spectra of the films with different Ge content annealed at $600{ }^{\circ} \mathrm{C}$ for $15 \mathrm{~min}$ in nitrogen atmosphere. The Ge content is mentioned in the figures. Curves 4 in both figures correspond to the same sample. Excitation wavelength is $532 \mathrm{~nm}$.

The increase of Ge content from $x=0.05$ up to $x=0.30$ caused the non-monotonic variation of the intensity of the PL component at 700-730 nm and its quenching with further $x$ rise (Fig.3,a). The intensities of other two PL bands changed also nonmonotonically with Ge content whereas for the samples with $x>0.3$ only these bands were detected being significantly overlapped (Fig.3,b). Similar PL emission centered at about $600 \mathrm{~nm}$ was reported in (36) for large Ge-ncs. It was shown that this PL band is due to Ge oxide shell covered Ge-ncs. Thus, one can assume that in our films with $x \geq 0.58$, the PL emission at 580-620 nm (Fig. 3b) is due to Ge oxide shell covered Ge-ncs. This statement can be supported by the fact that the variation of the Ge-ncs sizes from $3.8 \mathrm{~nm}(x=0.58)$ up to $8.2 \mathrm{~nm}(x=0.85)$ results in the variation of PL intensity only without any significant shift of PL peak position (Fig.3,b). The higher PL intensity for $x=0.58$ can be caused by the larger amount of corresponding emitting centers located in Ge oxide shell.

The PL band centered around 700-730 nm was found to be similar to PL emission reported for Ge-ncs embedded in $\mathrm{Al}_{2} \mathrm{O}_{3}$ host in (18). In that work, this PL band was ascribed to exciton recombination in Ge-ncs with the sizes $d=6.6-7.1 \mathrm{~nm}$. However, simple confinement model did not consider that the carriers confined in the nanocrystals are under a finite potential (18). At the same time, the band at 700-730 nm (1.69-1.77 eV) is significantly shifted in comparison with Ge bandgap $(0.66 \mathrm{eV})$. This fact was explained by the dependence of confinement potential on surrounding matrix caused by the conduction and valence band offsets between the Ge-ncs and $\mathrm{Al}_{2} \mathrm{O}_{3}$ matrix. Besides, the modification of Ge-ncs bandgap induced by the polarization interface charge was also taken into account since it may also play an important role due to the difference in dielectric constant of the host matrix and the Ge nanocrystals.

As it was shown by XRD and Raman scattering study described above, our samples did not demonstrate the formation of Ge-ncs in the films with $x<0.3$. In this regard, one can assume that the PL band at $700-730 \mathrm{~nm}$ can be caused by the recombination of carriers in amorphous Ge clusters being affected by surrounded $\mathrm{Al}_{2} \mathrm{O}_{3}$ host. At the same time, this PL band can originate also from the defects located in the vicinity of Ge- 
cluster/ $\mathrm{Al}_{2} \mathrm{O}_{3}$ interface. Since PL band centered at 700-730 nm was not observed in pure $\mathrm{Al}_{2} \mathrm{O}_{3}$ films, one can assume that the defect responsible for such emission is constructed from $\mathrm{Ge}, \mathrm{Al}$ and $\mathrm{O}$ atoms. Based on the obtained results one can concluded that the complex nature of PL spectrum is determined by the contribution of different recombination channels. However, additional study of PL emission in infrared spectral range as well as temperature behavior of PL spectrum can help to discriminate the contribution of carrier recombination via the Ge-ncs and different defects in light emission process. These experiments are in progress.

\section{Conclusions}

The evolution of optical and structural properties of Ge-doped $\mathrm{Al}_{2} \mathrm{O}_{3}$ films with different Ge content was investigated. As-deposited films and those annealed at $\mathrm{T}_{\mathrm{A}}=550{ }^{\circ} \mathrm{C}$ were found to be amorphous whatever $\mathrm{Ge}$ content. The formation of $\mathrm{Ge}$ nanocrystals was observed after treatment at $\mathrm{T}_{\mathrm{A}}=600^{\circ} \mathrm{C}$ during $1-15 \mathrm{~min}$. The higher $\mathrm{Ge}$ content, the shorter annealing time was required to form Ge nanocrystals. This annealing stimulated also an appearance of photoluminescence in visible-near infrared spectral range. Three PL bands peaked at about $590-600 \mathrm{~nm}, 620-630 \mathrm{~nm}$ and $700-730 \mathrm{~nm}$ were detected. Their relative contribution was depended on Ge content determining the shape and peak position of luminescence spectrum. Two former components were ascribed to the carrier recombination via Ge oxide shell covered Ge-ncs. The band peaked at 700-730 $\mathrm{nm}$ was assumed to originate from carrier recombination in amorphous Ge clusters or via defects at $\mathrm{Ge}$-cluster $/ \mathrm{Al}_{2} \mathrm{O}_{3}$ interface. The approach for the rough express estimation of the Ge excess content in the films based on the application of the spectroscopic ellipsometry technique was proposed.

\section{Acknowledgments}

The authors would like to thank for financial support the National Academy of Sciences of Ukraine and the Ministry of Education and Sciences of Ukraine (the project 89452), the National Research, Development and Innovation Office of Hungary (the project OTKA K131515 "Low-dimensional nanomaterials for the optical sensing of organic molecules on liquid and gas interfaces").

\section{References}

1. L.T. Canham, Appl. Phys. Lett., 57, 1046-1048 (1990).

2. V. Lehmann and U. Gösele, Appl. Phys. Lett. 58, 856 (1991).

3. L. Khomenkova, N. Korsunska, V. Yukhimchuk, A. Vivas Hernandez, A. Many, Y. Goldstein, E. Savir and J. Jedrzejewski, J. Lumin., 102, 705 (2003).

4. N. Korsunska, L. Khomenkova, O. Kolomys, V. Strelchuk, A. Kuchuk, V. Kladko, T. Stara, O. Oberemok, B. Romanyuk, P. Marie, J. Jedrzejewski, I. Balberg, Nanoscale Res. Lett. 8, 273 (2013).

5. M. L. Ciurea and A. M. Lepadatu, Digest J Nanomater. Biostruct., 10, 59 (2015).

6. H. Rinnert, M. Vergnat, Physica E, 16, 382 (2003). 
7. L. Khomenkova, M. Baran, J. Jedrzejewski, C. Bonafos, V. Paillard, Ye. Venger, I. Balberg and N. Korsunska, AIMS Mater. Sci. 3, 538 (2016).

8. S.K. Ray, S. Das, R. K. Singha, S. Manna, A. Dhar, Nanoscale Res. Lett., 6, 224 (2011).

9. D. Khomenkov, Y.-T. An, X. Portier, C. Labbe, L. Khomenkova, Mater. Res. Soc. Symp. Proc., 1617, 85 (2013).

10. L. Khomenkova, O. Kolomys, M. Baran, V. Strelchuk, A. V. Kuchuk, V. P. Kladko, J. Jedrzejewski, I. Balberg, Y. Goldstein, P. Marie, F. Gourbilleau, N. Korsunska, Adv. Mat. Res. 854, 117 (2014).

11. S. Hayashi, M. Ito and H. Kanamori, Solid State Commun., 44, 75 (1982).

12. Y.M. Niquet, G. Allan, C. Delerue, M. Lannoo, Appl. Phys. Lett., 77, 1182 (2000).

13. K. Yamamoto, S. Hayashi and M. Fujii, Jpn. J. Appl. Phys. 28, L1464 (1989).

14. Y. Maeda, N. Tsukamoto, Y. Yazawa, Y. Kanemitsu, Y. Masumoto, Appl. Phys. Lett. 59, 3168 (1991).

15. M. Y. Chan, P. S. Lee, V. Ho and H. L. Seng, J. Appl. Phys. 102, 094307 (2007).

16. L. Khomenkova, X. Portier, M. Carrada, C. Bonafos, B. S. Sahu, A. Slaoui and F. Gourbilleau, ECS Trans., 45(3), 331 (2012).

17. C. Bonafos, M. Carrada, G. Benassayag, S. Schamm-Chardon, J. Groenen, V. Paillard, B. Pecassou, A. Claverie, P. Dimitrakis, E. Kapetanakis, V. IoannouSougleridis, P. Normand, B. Sahu, A. Slaoui, Mat. Sci. Semicond. Proc., 15, 615 (2012).

18. S. Das, R. Aluguri, S. Manna, R. Singha, A. Dhar, L. Pavesi and S. K. Ray, Nanoscale Res. Lett. 7, 143 (2012).

19. E. G. Barbagiovanni, D. J. Lockwood, P. J. Simpson and L. V. Goncharova, J. Appl. Phys. 111, 034307 (2012).

20. O. Millo, I. Balberg, D. Azulay, T.K. Purkait, A. K. Swarnakar, E. Rivard and J. G. C. Veinot, J. Phys. Chem. Lett., 6, 3396 (2015).

21. D. Lehninger, J. Beyer and J. Heitmann, Phys Stat. Sol. A 155, 1701028 (2018).

22. S. Cosentino, Pei Liu, Son T. Le, S. Lee, D. Paine, A. Zaslavsky, D. Pacifici, S. Mirabella, M. Miritello, I. Crupi and A. Terrasi, Appl. Phys. Lett. 98, 221107 (2011).

23. I. Stavarache, V. S. Teodorescu, P. Prepelita, C. Logofatu and M. L. Ciurea, Sci. Rep. 9, 10286 (2019).

24. A. Lepadatu, A. Slav, C. Palade, I. Dascalescu, M. Enculescu, S. Iftimie, S. Lazanu, V. S. Teodorescu, M. L. Ciurea and T. Stoica, Sci. Rep. 8, 4898 (2018).

25. Y. Kamata, Materials Today, 11, 30 (2008).

26. M. Y. Chan, P. S. Lee, V. Ho and H. L. Seng, J. Appl. Phys., 102, 094307 (2007).

27. N. Korsunska, T. Stara, V. Strelchuk, O. Kolomys, V. Kladko, A. Kuchuk, L. Khomenkova, J. Jedrzejewski and I. Balberg, Physica E, 51, 115 (2013).

28. G. N. van den Hoven, E. Snoeks, A. Polman, J. W. M. van Uffelen, Y. S. Oei and M. K. Smit, Appl. Phys. Lett., 62, 3065 (1993).

29. M. K. Smit, G. A. Acket and C. J. van der Laan, Thin Solid Films, 138, 171 (1986).

30. L. Khomenkova, X. Portier, J. Cardin and F. Gourbilleau, Nanotechnology, 21, 285707 (2010).

31. L. Khomenkova, C. Labbé, X. Portier, M. Carrada and F. Gourbilleau, Phys. Stat. Sol. A, 210, 1532 (2013).

32. J. Gangwar, B. K. Gupta, S. K. Tripathi and A. K. Srivastava, Nanoscale, 7, 13313 (2015). 
33. Sh. Peng, D. Hu and D. He, Appl. Surf. Sci., 258, 6003 (2012).

34. M. Buljan, N. Radic, M. Ivanda, I. Bogdanovic-Radovic, M. Karlusic, J. Grenzer, S. Prucnal, G. Drazic, G. Pletikapic, V. Svetlicic, M. Jercinovic, S. Bernstorff, V. Holy, J. Nanopart. Res., 15, 1485 (2013).

35. S. Yin, E. Xie, C. Zhang, Z. Wang, L. Zhou, I. Z. Ma, C. F. Yao, H. Zang, C. B. Liu, Y. B. Sheng and J. Gou, Nucl. Instrum. Methods. B., 12, 2998 (2008).

36. O. Millo, I. Balberg, D. Azulay, T.K. Purkait, A. K. Swarnakar, E. Rivard and J. G. C. Veinot, J. Phys. Chem. Lett., 6, 3396 (2015). 